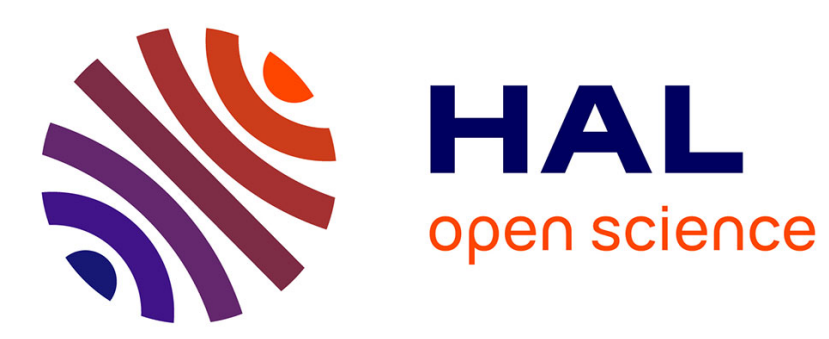

\title{
Absolute photoionization cross sections of the acceptor state level of chromium in indium phosphide
}

\author{
G. Bremond, G. Guillot, A. Nouailhat, G. Picoli
}

\section{To cite this version:}

G. Bremond, G. Guillot, A. Nouailhat, G. Picoli. Absolute photoionization cross sections of the acceptor state level of chromium in indium phosphide. Journal of Applied Physics, 1986, 59 (6), pp.2038-2043. hal-02023645

\section{HAL Id: hal-02023645 \\ https://hal.science/hal-02023645}

Submitted on 27 Feb 2019

HAL is a multi-disciplinary open access archive for the deposit and dissemination of scientific research documents, whether they are published or not. The documents may come from teaching and research institutions in France or abroad, or from public or private research centers.
L'archive ouverte pluridisciplinaire HAL, est destinée au dépôt et à la diffusion de documents scientifiques de niveau recherche, publiés ou non, émanant des établissements d'enseignement et de recherche français ou étrangers, des laboratoires publics ou privés. 


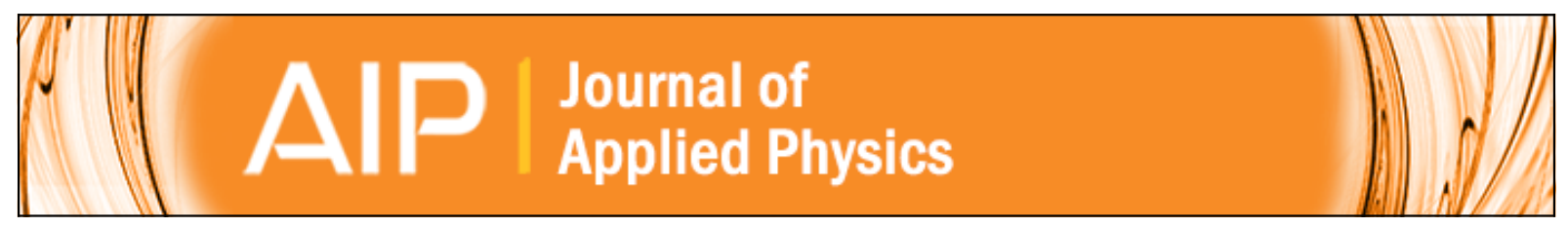

\section{Absolute photoionization cross sections of the acceptor state level of chromium in indium phosphide}

G. Bremond, G. Guillot, A. Nouailhat, and G. Picoli

Citation: Journal of Applied Physics 59, 2038 (1986); doi: 10.1063/1.336387

View online: http://dx.doi.org/10.1063/1.336387

View Table of Contents: http://scitation.aip.org/content/aip/journal/jap/59/6?ver=pdfcov

Published by the AIP Publishing

\section{Articles you may be interested in}

State-dependent photoionization cross-sections of $3 \mathrm{~d}$ transition metal atoms

J. Chem. Phys. 136, 174304 (2012); 10.1063/1.4707931

Absolute Photoionization Cross Section with an Ultrahigh Energy Resolution for Ne in the Region of 1s Rydberg States

AIP Conf. Proc. 879, 1121 (2007); 10.1063/1.2436260

Identification of a nickel doubleacceptor state in indium phosphide

Appl. Phys. Lett. 55, 1085 (1989); 10.1063/1.101712

Photoionization of vapor phase thallium and indium monohalides in the ultraviolet: Absolute cross sections and photofragment spectroscopy by photodetachment of I-

J. Chem. Phys. 81, 5336 (1984); 10.1063/1.447676

Measurement of concentration and photoionization cross section of indium in silicon

J. Appl. Phys. 54, 3926 (1983); 10.1063/1.332566

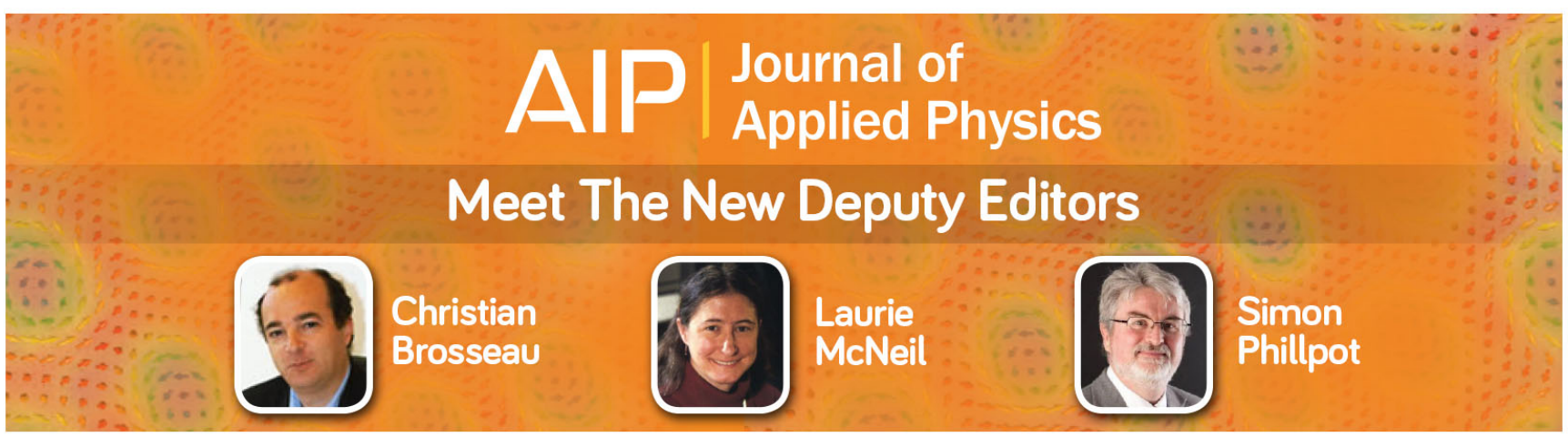




\title{
Absolute phofolonization cross sections of the acceptor state level of chromium in indium phosphide
}

\author{
G. Bremond, G. Guillot, and A. Nouailhat \\ Laboratoire de Physique de la Matière (Laboratoire associé au CNRS No. 358), Institut National des Sciences \\ Appliquées de Lyon, 20, Avenue Albert Einstein, 69621 Villeurbanne Cédex, France \\ G. Picoli \\ C.N.E.T. LAB/ICM, Route de Trégastel, 22301 Lannion Cédex, France
}

(Received 6 June 1985; accepted for publication 28 October 1985)

\begin{abstract}
We have studied by deep-level transient spectroscopy and deep-level optical spectroscopy $n$-type chromium-doped InP. We definitively confirm that the $\mathrm{Cr}^{2+} / \mathrm{Cr}^{3+}$ acceptor state is positioned at $E_{C}-0.4 \mathrm{eV}$ in $\mathrm{InP}$. We have measured for the first time the absolute values of the photoionization cross sections of $\mathrm{Cr}^{2+}$ in InP by deep-level optical spectroscopy. The $\sigma_{n}^{0}$ cross section exhibits both a resonant and a nonresonant character. The former corresponds to the internal transition ${ }^{5} T_{2} \rightarrow{ }^{5} E$ of $\mathrm{Cr}^{2+}$, while the latter is attributed to the photoexcitation from the $\mathrm{Cr}^{2+}$ to the conduction band. The threshold of this transition at $E_{C}-0.41 \mathrm{eV}$ indicates a very small Franck-Condon shift. The scales of the absolute photoionization values $\left(\sigma_{n}^{0}\right)$ and photoneutralization $\left(\sigma_{p}^{0}\right)$ cross sections towards the conduction and valence bands are the same, which seems to indicate no selection rules.
\end{abstract}

\section{IRTRODUCTION}

The introduction of transition-metal ions as dopants into III-V compounds produces electronic properties which are of great interest from a theoretical point of view and useful from a practical one: the manufacturing of semi-insulating (s.i.) substrates of good quality used in planar technology in the fields of fast electronic and optoelectronic devices. The role of chromium in InP has been recently investigated by numerous techniques ${ }^{1-6}$ in order to explain the compensation mechanism. Chromium doping produces semi-insulating material with resistivities of only about $10^{4}$ $\Omega \mathrm{cm}$ (by comparison, $\operatorname{InP}$ :Fe s.i. has a resistivity of $10^{8}$ $\Omega \mathrm{cm}$ ).

Iseler ${ }^{1}$ located by Hall and resistivity measurements a level associated with chromium at $E_{\mathrm{C}}-0.39 \mathrm{eV}$ in s.i. InP, assigning this level to the $\mathrm{Cr}_{\mathrm{In}}^{2+/ 3+}$ acceptor one. This result was confirmed by the photoconductivity measurements of Fung and Nicholas ${ }^{3}$ : They located the $\mathrm{Cr}^{2+13+}$ acceptor level at $E_{C}-0.4 \mathrm{eV}\left(E_{C}-0.47 \mathrm{eV}\right)$ at $300 \mathrm{~K}(4 \mathrm{~K})$. On the other hand, the photoconductivity threshold found by Eaves et $a l^{2}$ leads to a very different conclusion.

In photoluminescence measurements, Koschel, Bischop, and McCombe ${ }^{4}$ observed a band peaking at $0.85 \mathrm{eV}$ that they attributed to the internal transition ${ }^{5} E \rightarrow{ }^{5} T_{2}$ of the $\mathrm{Cr}_{\mathrm{In}}^{2}+$. The same interpretation has been given by Barrau $e t$ al., ${ }^{5}$ who observed a zero-phonon structure at $0.886 \mathrm{eV}$ associated with the $0.85-\mathrm{eV}$ band. These results should locate the ${ }^{5} E$ excited state below the conduction-band minimum, and thus the chromium levell lies around $E_{C}-0.9 \mathrm{eV}$, in agreement with Eaves et al. results ${ }^{2}$ but in contradiction with the Iseler ${ }^{1}$ and Fung and Nicholas ${ }^{3}$ results. Our first results ${ }^{6}$ using deep-level transient spectroscopy and deep-level optical spectroscopy techniques (DLTS-DLOS) were well interpreted by the chromium acceptor level at $0.4 \mathrm{eV}$ below the conduction band, which was labeled IE3.
The aim of this paper is first to confirm definitively the position of the chromium acceptor level in InP and second to give absolute information on the spectrum of the photoionization cross sections $\sigma_{n}^{0}$ and $\sigma_{p}^{0}$ of IE3. The possibility of determining the absolute values of $\sigma_{n}^{0}$ and $\sigma_{p}^{0}$ is very important from a theoretical point of view. Indeed the photoionization cross sections can provide useful information, such as ionization energy of the level, coupling with the bands, and therefore some indications of the symmetry of defect wave functions.

In Sec. II, we give a description of the experimental technique used. The experimental results and discussion concerning InP:Cr are given in Secs. III and IV.

\section{EXPERIMENTAL PROCEDURE}

Samples come from a polycrystalline ingot, prepared by the conventional gradient freeze technique in a pyrolite boron nitride (PBN) crucible. ${ }^{7}$ The chromium concentration in the melt was $0.1 \%$ by weight, which is sufficient to reach the chromium solubility limit $\left(2 \times 10^{16} \mathrm{~cm}^{-3}\right)$ in the hot zone of the ingot. The studied samples come from the zone labeled $c$ as defined in Ref. 7. Spark-source mass spectroscopy reveals silicon and chromium as the main impurities. The samples are $n$ type $(\rho \sim 35 \Omega \mathrm{cm}$ at room temperature $)$. A doping profile measurement gives $N_{d}-N_{a} \simeq 6 \times 10^{14} \mathrm{~cm}^{-3}$ at $300 \mathrm{~K}$. The experimental results reported below for $\mathrm{Cr}^{2+13+}$ in InP have been obtained using gold Schottky barriers of area $0.8 \mathrm{~mm}^{2}$ on $n$-type $\mathrm{ln}$ ?. Before gold vaporization, first, the ohmic contacts are provided by small dots of Sn on the sides of the samples at $300^{\circ} \mathrm{C}$ under hydrogen flow, and second, the surface is prepared by a standard cleaning and etching procedure followed by natural oxidation in dry atmosphere to increase the apparent Schottky barrier and thus to lower the leakage current of the diode under reverse bias conditions. ${ }^{8}$ The examined sample is mounted in a liq- 
uid- $\mathrm{N}_{2}$ cryostat or liquid-He cryostat, the window of this being made of $\mathrm{CaF}_{2}$ and analyzed by DLTS and DLOS techniques.

DLTS measurements permit one to determine the apparent activation energy $\Delta E_{a}$ and the thermal capture cross section from the relation

$$
\frac{e_{n, p}}{T^{2}}=3.25 \times 10^{25} g_{n, p} \sigma_{\infty}\left(\frac{m_{n, p}^{*}}{m_{0}}\right) \exp \left(-\frac{\Delta E_{a}}{k T}\right),
$$

where $e_{n, p}$ is the coefficient for thermal emission of carriers (electron or hole) from the trapping center, $g_{n, p}$ the degeneracy factor, and $m_{n, p}^{*}$ the electron (hole) effective mass at the minimum conduction (valence) band. The plot of $\log \left(e_{n, p} / T^{2}\right)$ as a function of $1 / T$ is usually called the "signature" of the level.

For the DLOS experiment, the temperature of the sample is fixed so the thermal emission of carriers is neglected. The main feature of the DLOS technique is to use the fact that the derivative at time $t=0$ of the photocapacitance transient, expressing the level occupancy in a reverse-biased junction capacitance, is directly related to $\sigma_{n}^{0}(h v)$ or $\sigma_{p}^{0}(h v)$ if initial conditions-all traps filled or empty-are fixed. These initial conditions are determined by various modes of operations-electrical, thermal or optical excitationwhich depend on the trap characteristics and material type. ${ }^{9}$ For one electron trap of concentration $N_{T}$ in an $n$-type material, the variation of charge due to the level at time $t=0$ after a direct bias pulse to fill all the traps is

$$
\left.\frac{d n}{d t}\right|_{t=0}=\sigma_{n}^{0}(h v) N_{T} \phi(h v)
$$

$\phi(h v)$ is the photon flux at energy $h v$ per surface unity in the depletion layer. This charge variation leads to a variation of the capacitance value $C$ of the Schottky given by

$$
\frac{1}{C} \frac{d C}{d t}=\frac{1}{2 n_{e}} \frac{d n}{d t}\left(1-\frac{\lambda}{W}\right)^{2} \text {, }
$$

with $n_{e}$ the density of charge carriers, $W$ the depletion zone width at reverse bias, and $\lambda$ the zone width where the trap level is below the Fermi level.

From Eqgs. (2) and (3) we have

$$
\left.\frac{d C}{d t}\right|_{t=0}=\frac{C N_{T}}{2 n_{e}}\left(1-\frac{\lambda}{W}\right)^{2} \sigma_{n}^{0}(h v) \phi(h v) \text {. }
$$

With the same capacitance measurement conditions, the DLTS peak of amplitude $\Delta C$ corresponding to the level gives

$$
\frac{\Delta C}{C}=\frac{N_{T}}{2 n_{e}}\left(1-\frac{\lambda}{W}\right)^{2}
$$

From Eqs. (4) and (5) we have

$$
\left.\frac{d C}{d t}\right|_{t=0}=\Delta C \sigma_{n}^{0}(h v) \phi(h v) \text {. }
$$

The DLOS signal is

$$
S(h v)=\left.\frac{1}{\phi(h v)} \frac{d C}{d t}\right|_{t=0} .
$$

From (6) and (7) we have

$$
\sigma_{n}^{a}(h v)=\frac{S(h v)}{\Delta C} \text {. }
$$

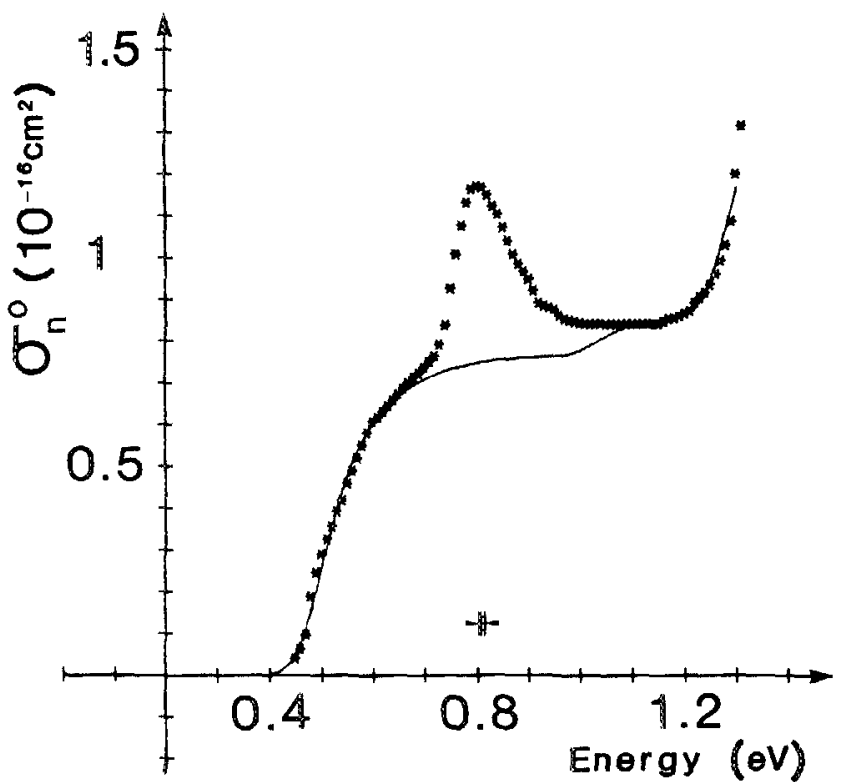

FIG. 1. Photoionization cross section $\sigma_{n}^{0}(h \nu)$ of the IE3 level obtained by electrical DLOS at $T=89 \mathrm{~K}$.", experimental points; -, fit of the nonresonant part of the photoionization cross section (see text).

To obtain the absolute value of $\sigma^{0}(h v)$, it is necessary to know the photon flux $\phi(h v)$ acting in the junction for the whole energy range [Eqs. (7) and (8)]. The DLOS apparatus has been already described. ${ }^{9}$ We use different monochromators for exciting light: a Perkin-Elmer 112B with a KBr of LiF prism, or a Bausch and Lomb high-intensity monochromator with $675-$ line $/ \mathrm{mm}$ grating, blazed at $1 \mu \mathrm{m}$ or

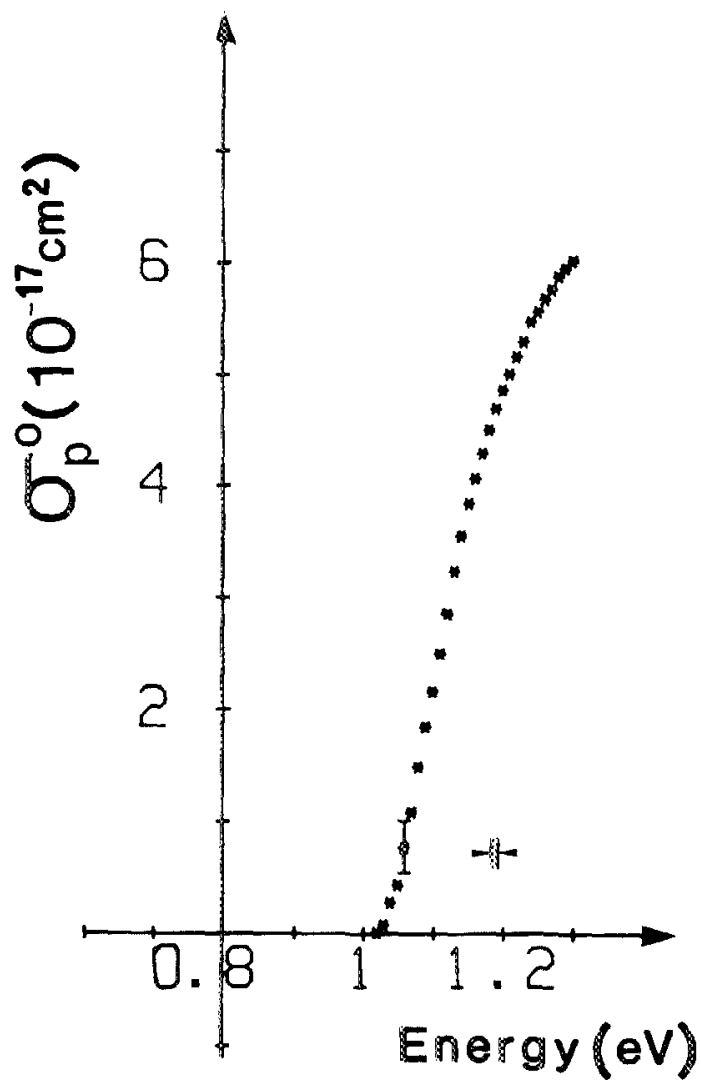

FIG. 2. Photoionization cross section $\sigma_{p}^{0}(h v)$ of the IE3 level obtained by thermal DLOS at $T=157 \mathrm{~K}$. 
337.5 -line $/ \mathrm{mm}$ grating blazed at $2 \mu \mathrm{m}$. The exciting sources that cover the entire energy range between 0.15 and $1.5 \mathrm{eV}$ are Globar and tungsten light sources. The different cycles (electrical excitation, change of photon wavelength, temperature regulation, data acquisition and processing) are made by an on-line computer. The measure of the absolute value of the photon flux energy $\phi(h v) h v$ is performed by a sensitive pyroelectric detector Optilas KT3110, localized at the same position as the sample. Corrections are brought about following the experimental conditions. If the illumination is done on the side of the vaporized gold layer, the transmission was measured for this layer (semitransparent in this case) and taken into account for the exact value of $\phi(h v)$. If the illumination is done on the back side of the Schottky barrier, we use gold, mirrorlike, thick layers. The absolute measurements of $\sigma_{n}^{0}$ and $\sigma_{p}^{0}$ of the $\mathrm{Cr}^{2+/ 3+}$ level in $\mathrm{InP}: \mathrm{Cr}$ have been made over the entire gap energy range.

\section{EXPERIMENTAL RESULTS ON InP:Cr}

Two samples are intensively examined and give the same results. We observe in the samples only one main deep electron level $\left(\Delta E_{a}=0.40 \mathrm{eV}, \sigma_{\infty}=5 \times 10^{-15} \mathrm{~cm}^{2}\right)$, which has exactly the same thermal signature as the trap we have called IE3. In Ref. 6, we tentatively attributed this defect to the chromium acceptor level $\mathrm{Cr}^{2+/ 3+}$ mainly because it was observed in $n$-type vapor-phase epitaxy (VPE) layers grown on s.i. substrates doped with $\mathrm{Cr}$ and it is well known that $\mathrm{Cr}$ can out-diffuse from the substrate to the epilayer. In the determination of the IE3 parameters, the following values are used: $g_{n}=1, m_{n}^{*} / m_{0}=0.078$. The determined concentration of electrically active chromium is $3 \times 10^{14} \mathrm{~cm}^{-3}$.

The absolute optical cross sections $\sigma_{n}^{0}(h v)$ and $\sigma_{p}^{0}(h v)$ are given in Figs. 1 and 2. For $\sigma_{n}^{0}$, we can observe an experimental onset at about $0.41 \mathrm{eV}$ and a broad peak centered at $0.8 \mathrm{eV}$. This peak cannot be explained by the theory of the optical cross section for the transition between a deep level and the conduction band. We give in Fig. 1, for illustration, the best fit given by the phenomenological model we used to analyze the optical cross sections of the deep levels in III-V compounds. ${ }^{9}$ This analysis has been made in details for the deep $\mathrm{Cr}$ level in GaAs. ${ }^{10}$

The fit of Fig. 1 corresponds to the following values of the model parameters:

$\begin{array}{cccccccc}\text { Binding energy } & E_{n} & E_{n}^{0} & d_{\mathrm{FC}} & P_{\mathrm{r}} & P_{\mathrm{L}} & P_{X} & \alpha^{-1} \\ 0.4 \mathrm{eV} & 0.475 \mathrm{eV} & 75 \mathrm{meV} & 1 & 0.0065 & 0.064 & 0.5 \AA\end{array}$

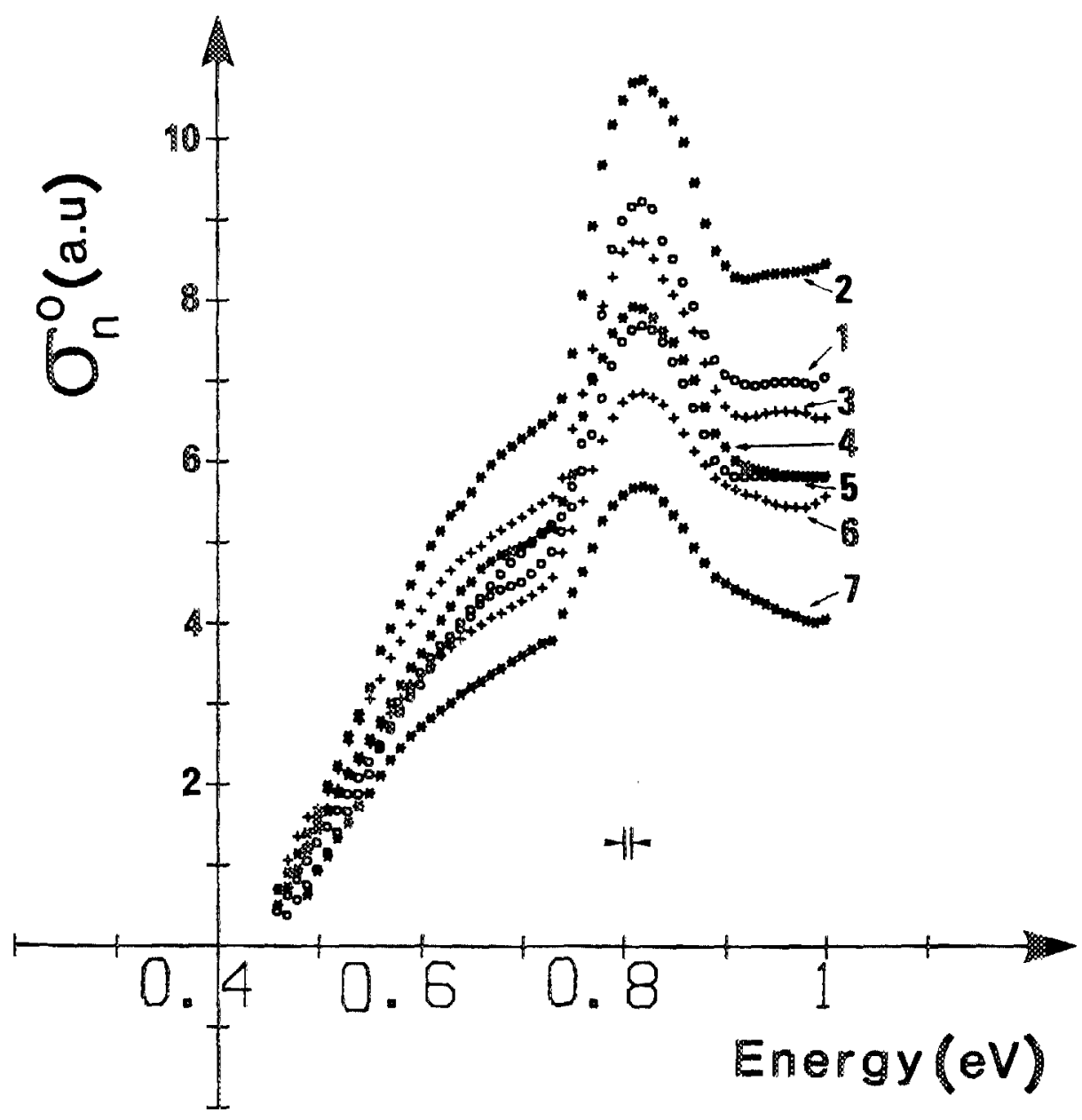

FIG. 3. Photoionization cross sections $\sigma_{n}^{0}(h v)$ of the IE3 level at different temperatures. 1, $T=9 \mathrm{~K} ; 2, T=33 \mathrm{~K} ; 3$, $T=63 \mathrm{~K} ; 4, T=80 \mathrm{~K} ; 5, T=99 \mathrm{~K} ; 6$, $T=120 \mathrm{~K} ; 7, T=136 \mathrm{~K}$. 
Here $E_{n}^{0}$ is the optical ionization energy, $d_{\mathrm{FC}}$ is the FranckCondon energy $\left(E_{n}^{0}=E_{n}+d_{\mathrm{FC}}\right), P_{\Gamma}, P_{L}$, and $P_{X}$ are weighting factors adjusted in order to fit the transitions towards the $\mathbb{\Gamma}, L$, and $X$ bands, respectively, and $\alpha^{-1}$ gives information on the wave-function extension of the bound electron. In the mathematical formulation, ${ }^{9}$ we consider the electronic transitions allowed and the deep trap potential as a Dirac one.

Figure 3 shows $\sigma_{n}^{0}$ at different temperatures. The halfwidth of the $0.8-\mathrm{eV}$ band can be classically analyzed, considering this one as Gaussian. ${ }^{11}$ The shape of the band is then given by

$$
\sigma_{G}^{0}=B \exp \left(-\frac{\left(h \nu-E_{0}\right)^{2}}{2 \sigma^{2}}\right)
$$

where $B$ is the normalization parameter, $E_{0}$ is the energy of the maximum, and

$$
\begin{aligned}
& \sigma=\sigma_{0}\left(\operatorname{coth} \frac{\hbar \omega}{2 k T}\right)^{1 / 2}, \\
& \sigma_{0}=S^{1 / 2} \hbar \omega .
\end{aligned}
$$

We use generally the value of the half-width:

$$
W(T)=2 \sigma(2 \ln 2)^{1 / 2} .
$$

In these expressions, the symbols have their usual meaning, $S$ being the Huang-Rhys factor and $\hbar \omega$ the effective phonon energy which is coupled to the level. In the fundamental state, the Franck-Condon shift is given by

$$
d_{\mathrm{FC}}=S \hbar \omega .
$$

The results of the best fit (Fig. 4) are

$$
\begin{aligned}
& W(0 \mathrm{~K})=79 \pm 2 \mathrm{meV}, \\
& \hbar \omega=15 \mathrm{meV}, \\
& S=5,
\end{aligned}
$$

so

$$
d_{\mathrm{FC}}=S \hbar \omega=75 \mathrm{meV} .
$$

\section{DISCUSSION}

\section{A. Evidence of the $\mathrm{Cr}^{2+/ 3+}$ acceptor leve}

Following our DLTS measurements on bulk samples InP:Cr and the VPE layer on a $\mathrm{Cr}$-doped substrate, we can claim without ambiguity that IE3 is clearly connected with the presence of chromium. The photoionization cross section $\sigma_{n}^{0}$ of IE3 shows a very characteristic resonance at 0.8 $\mathrm{eV}$, the bottom of that band being at $0.76 \mathrm{eV}$. This latter transition has been recently observed by Clerjaud et al. ${ }^{12}$ in optical absorption. The zero-phonon line of that band is located at $0.756 \mathrm{eV}$ with a fine structure typical of the internal transition of $\mathrm{Cr}^{2+}$ in III-V compounds. ${ }^{13}$ This fact means that in our experiment we perform photoionization of $\mathrm{Cr}^{2+}$ in its ground state ${ }^{5} T_{2}$. As a consequence the threshold at $0.41 \mathrm{eV}$ gives the energy level of $\mathrm{Cr}^{2+13+}$ in agreement with other authors. ${ }^{13,14,15}$ The excited state ${ }^{5} E$ is the conduction band. So, as it is shown by the analysis of $\sigma_{n}^{0}$, we can distinguish for $\sigma_{n}^{o}$ two kinds of transitions, namely the internal and

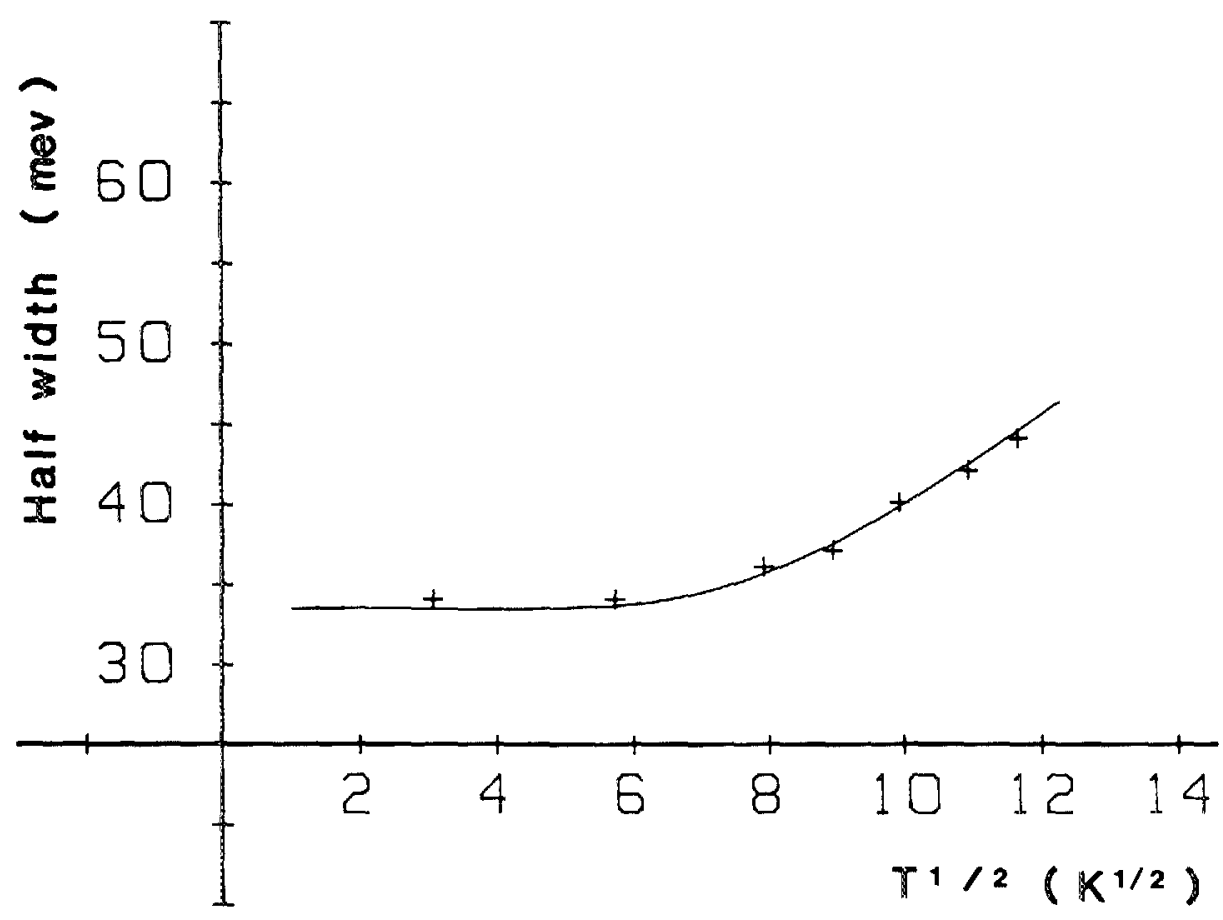

FIG. 4. Temperature dependence of the $0.8-\mathrm{eV}$ band half-width $W(T)$, + , experimental points; - best fit [Eq. (12) with $W(4 \mathrm{~K})=79 \mathrm{meV}, \hbar \omega=15 \mathrm{meV}$, $S=5]$. 


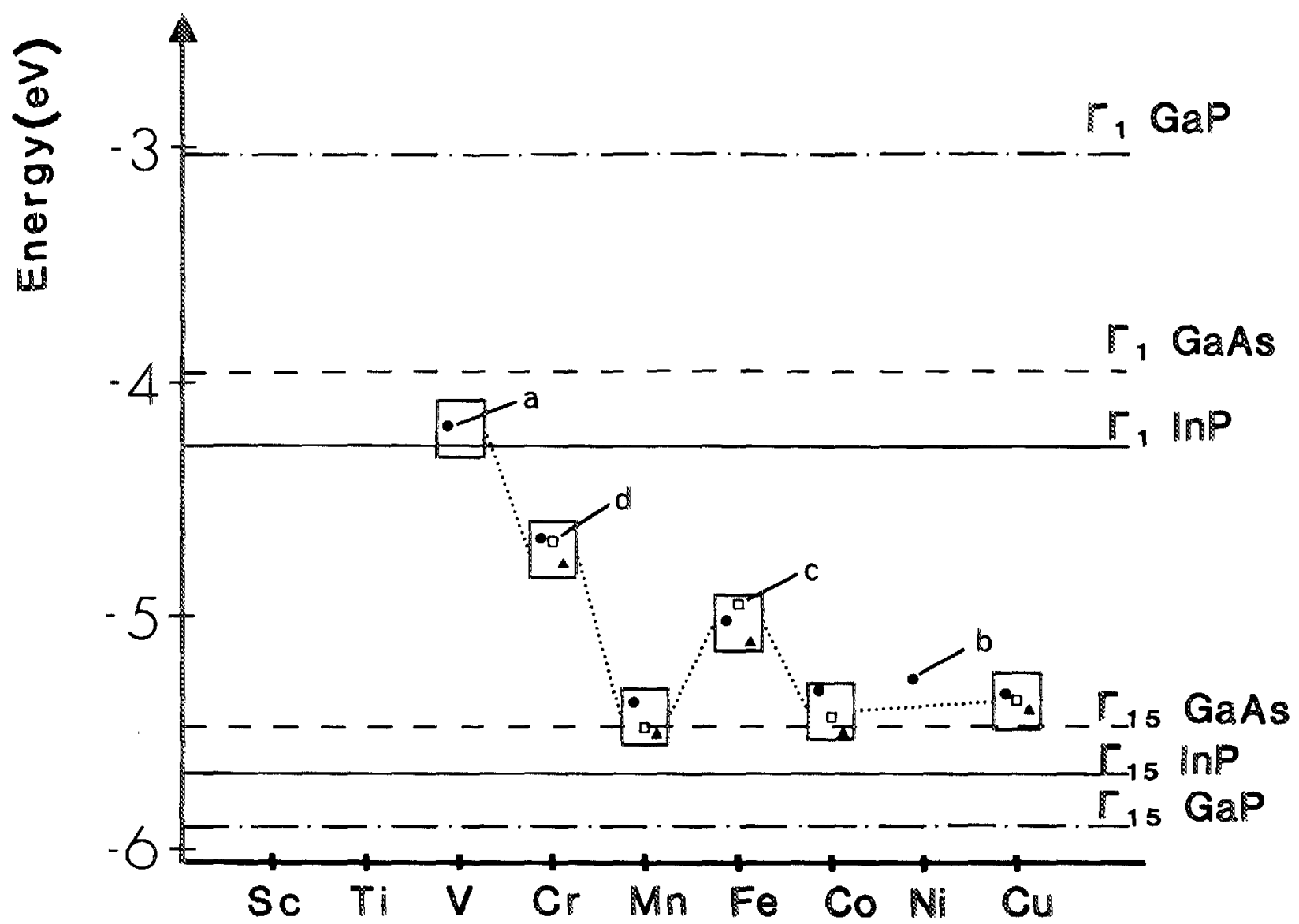

FIG. 5. Acceptor states $\left(M^{2+} / M^{3+}\right)$ for the $3 d$ transition metal in GaAs, InP, and GaP related to vacuum, $\bullet, G a A s ; \square$, InP; $\Delta, G a P . a$ indicates data from Ref. $20 ; b$ from Ref. $21 ; c$ from Ref. $22 ; d$, this work. Other data are from Ref. 19.

the photoionization transitions. The former is written in our context

$$
{ }^{5} T_{2}+h v \rightarrow{ }^{2 s+1} \Gamma
$$

where $S$ and $\Gamma$ are labels of the final state. These excitations are currently described in the framework of the crystal. field ${ }^{16}$ or molecular scheme. ${ }^{17}$ The photoionization transition is written

${ }^{5} T_{2}+h v \rightarrow{ }^{2 S+1} \Gamma+e^{-}$(in the conduction band).

The final state is that of $\mathrm{Cr}^{3+}$ with an electron going away. As usual we have supposed that $\mathrm{Cr}^{3+}$ is its ground state ${ }^{4} T_{1}$, but $\mathrm{Cr}^{3+}$ can be in an excited state in the final state of the transition. ${ }^{18}$ The use of a Dirac potential in the mathematical formulation ${ }^{9}$ for the best theoretical fit of the photoionization transition is in agreement with an acceptor state.

\section{B. Trends in level positions}

It is interesting to compare the thermal ionization energy of the $\mathrm{Cr}^{2+}$ charge state $(0.4 \mathrm{eV})$ in InP with the other III. $V$ compounds: GaAs and $\mathrm{GaP}$. It is expected that a deep level related to a given transition metal is mainly tied to the vacuum and independent of the host lattice in III.V compounds. ${ }^{19}$ We have reported in Fig. 5 the well-established ionization energies of the acceptor state related to chromium on an absolute energy scale and the principal band edges. The absolute impurity level for $\mathrm{Cr}_{1 \mathrm{n}}^{2+/ 3+}$ is well linked to the vacuum. Moreover, the energy position of the $\mathrm{Cr}_{1 n}^{2+/ 3+}$ acceptor state level in InP is consistent with the general trend of the deep-level positions of transition elements in III-V compounds. $^{23}$

\section{Transition ${ }^{B} T_{2} \rightarrow \mathrm{B} E$}

The band at $0.8 \mathrm{eV}$ corresponds to the internal transition ${ }^{5} T_{2} \rightarrow{ }^{5} E$ of $\mathrm{Cr}^{2+}$; it is interesting to make a comparison with the same transition in GaAs (see Table I). If we neglect the electron phonon coupling in the excited state ${ }^{5} E$, we can interpret the Franck-Condon shift as a result of the JahnTeller coupling in the ground state ${ }^{5} T_{2}$. So, the two systems exhibit the same Jahn-Teller energy ( $\sim 70 \mathrm{meV})$.

Moreover, the effective mode energies clearly depend on the methods that have been used by different authors. Some of them use the separation Shiw between the zero-phonon line and the maximum of the band together with the ratio $e^{-s}$ between the area of the zero-phonon line and the area of the full band. Other authors, as we did, extract the effective mode energy from the dependence of the width on temperature.

We believe that the discrepancy between the two methods does not come from some error inherent to experiment 
TABLE I. Comparison of some characteristics of the internal transition ${ }^{5} T_{2} \rightarrow{ }^{5} E$ for $\mathrm{Cr}^{2+}$ in $\mathrm{GaAs}$ and $\mathrm{Cr}^{2+}$ in InP.

\begin{tabular}{lccccl}
\hline \hline & Transition & $\begin{array}{l}\hbar \omega_{\text {ef }} \\
(\mathrm{meV})\end{array}$ & $S$ & $\begin{array}{l}S \hbar \omega_{\mathrm{ef}} \\
(\mathrm{meV})\end{array}$ & References \\
\hline $\mathrm{Cr}^{2+}$ in GaAs & 0.820 & 15 & 5 & 75 & 10 \\
$\mathrm{Cr}^{2+}$ in GaAs & 0.820 & 9 & 8.5 & 75 & 18 \\
$\mathrm{Cr}^{2+}$ in InP & 0.756 & 15 & 5 & 75 & $\begin{array}{l}\text { Present } \\
\text { work }\end{array}$ \\
$\mathrm{Cr}^{2+}$ in InP & 0.756 & -8.7 & 7 & $\sim 60$ & 12 \\
\hline
\end{tabular}

but rather is due to the oversimplified models. As usual we have supposed that the coupling to one effective mode works. In fact, the center is coupled to many modes. So a possible explanation seems to be the breakdown of the approximation of single-mode coupling.

\section{Comparison between $\sigma_{n}^{0}$ and $\sigma_{\rho}^{\circ}$ optical cross sections}

In the widely employed crystal-field picture, ${ }^{16}$ the optjcal transitions from a $3 d$ trap state to the $s$-like conduction band are assumed to be parity-forbicden, whereas transitions from the $p$-like valence band to the trap are allowed. If we look to the nonresonant part of the photoionization cross section $\sigma_{n}^{0}$ (Fig. 1) we note that (i) the absolute values of the transition towards the conduction band $\left(\sigma_{n}^{0}\right)$ and towards the valence band $\left(\sigma_{p}^{0}\right)$ are both of the order of $10^{-16} \mathrm{~cm}^{2}$, and (ii) for the best fit of the nonresonant part of $\sigma_{n}^{0}$, we consider the electronic transitions allowed in the mathematical formulation.

Very recent experimental data on $\mathrm{Cr}$ in $\mathrm{ZnS}$ (Ref. 24) show the optical cross sections $\sigma_{n}^{0}$ and $\sigma_{p}^{0}$ to be both of the order of $10^{-17} \mathrm{~cm}^{2}$. So, as a consequence no selection rules seem to work. Recent theoretical calculations of Vogl and Baranowsiki ${ }^{25}$ show that the ratio $\sigma_{n}^{0} / \sigma_{p}^{0}$ is 1.23 for $\mathrm{Cr}$ in CdSe, in quantitative agreement with the data for $\mathrm{ZnS}: \mathrm{Cr}$ and our results for InP:Cr. This result reflects the extended hostlike character of the trap wave function which strongly couples to both $s$ - and $p$-type Bloch states and does not favor the model of a weak crystal field scheme.

In the case of $\mathrm{Cr}^{2+}, t_{2}$ orbitals of the fundamental state $\left({ }^{5} T_{2}\right)$ are partly hybridized with ligand orbitals, ${ }^{25}$ and transitions to the two bands have the same order of magnitude in contrast to what is observed for the vanadium donor level in InP $\left(\mathrm{V}^{3+14+}\right),{ }^{26}$ where the funcamental state has $e$ orbitals.

\section{CONCLUSION}

With our DiOS technique, we have experimentally shown the correlation between the onset at $0.4 \mathrm{leV}$ and the internal transition ${ }^{5} \mathrm{~T}_{2} \rightarrow^{5} E$ of $\mathrm{Cr}^{2+}$. This last fact allows us to locate the $\mathrm{Cr}^{2+} / \mathrm{Cr}^{3+}$ level $0.4 \mathrm{eV}$ below the conduction band.
We have measured the absolute cross sections of photoionization of $\mathrm{Cr}^{2+}$. We find similar values for both transitions to the conduction band and to the valence band. This result cannot be explained by a simple model of a parityallowed $\mathrm{Cr}^{3+} \rightarrow \mathrm{Cr}^{2+}$ process (from $p$-type valence band to the $d$ shell of $\mathrm{Cr}$ ) and a parity-forbidden $\mathrm{Cr}^{2+} \rightarrow \mathrm{Cr}^{3+}$ process (from the $d$ shell of $\mathrm{Cr}$ to the $s$-like conduction band). This effect can be ascribed to a strong hybridization of the impurity $3 d$ function with host wave functions.

\section{ACKNOWLEDGMENTS}

We are very grateful to Y. Toudic of CNET, Lannion, for providing the samples and B. Clerjaud for helpful discussions.

'G. W. Iseler, in Gallium Arsenide and Related Compounds, 1978, Inst. Phys. Conf. Ser. No. 45, edited by C. M. Wolfe (Institute of Physics, London, 1979). pp. 144-153.

${ }^{2}$ L. Eaves, T. Englert, T. Inston, C. Uihlein, P. J. Williams, and H. C. Wright, in Semi-Insulating III-V Materials, edited by G. J. Rees (Shiva, Orpington, 1980), pp. 145-153.

${ }^{3}$ S. Fung and R. J. Nicholas, J. Phys. C 14, 2135 (1981).

${ }^{4}$ W. H. Koschel, S. G. Bischop, and B. D. McCombe, in Physics of Semiconductors, edited by F. G. Fumi (Marves, Rome, 1979), pp. 1065-1068.

5J. Barrau, Do Xuan Thanh, M. Brousseau, J. C. Brabant, and F. Voillot, Physica 116B, 456 (1983).

${ }^{6} \mathrm{G}$. Bremond, A. Nouailhat, and G. Guillot, in Proceedings of the International Conference on GaAs and Related Compounds 1981, Inst. Phys. Conf. Ser. No. 63, edited by T. Sugano (Institute of Physics, London, 1982), p. 239.

${ }^{7}$ R. Coquille, Y. Toudic, M. Gauneau, G. Grandpierre, and J. C. Paris, J. Cryst. Growth 64, 23 (1983).

${ }^{8} \mathrm{G}$. Bremond, Thesis Docteur-Ingenieur, Lyon (1981).

${ }^{9}$ A. Chantre, G. Vincent, and D. Bois, Phys. Rev. B 23, 5335 (1981).

${ }^{10}$ A. Nouailhat, F. Litty, S. Loualiche, P. Leyral, and G. Guillot, J. Phys. 43, 815 (1982).

"D. Curie, in Optical Properties of Ions in Solids, edited by B. Di Bartolo (Plenum, New York, 1974), p. 70.

${ }^{12}$ B. Clerjaud, C. Naud, G. Picoli, and Y. Toudic, J. Phys. C 17, 6469 (1984).

${ }^{13}$ B. Clerjaud, A. M. Hennel, and G. Martinez, Solid State Commun. 33, 983 (1980).

${ }^{14}$ P. N. Nichols, I. Odeh, and J. Sladek, Solid State Commun. 34, 621 (1980).

15J. K. Rhee and P. K. Battachaya, J. Appl. Phys. 53, 4247 ( 1982).

${ }^{16} \mathrm{~S}$. Sugano, Y. Tanabe, and H. Kahimura, Multiplets of Transition Metal Ions in Crystals (Academic, New York, 1970).

${ }^{17}$ G. Picoli, A. Chomette, and M. Lannoo, Phys. Rev. B 30, 7138 (1984).

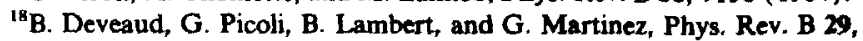
5749 (1984).

${ }^{10}$ L. A. Ledebo and B. K. Ridley, J. Phys. C 15, L961 (1982).

${ }^{20}$ F. Litty, P. Leyral, S. Loualiche, A. Nouailhat, and G. Guillot, Physica 117B\&118B, 182 (1983).

${ }^{21}$ L. A. Hemstreet, Phys. Rev. B 10, 4590 (1980).

${ }^{22}$ G. Bremond, A. Nouailhat, G. Guillot, and B. Cockayne, Solid State Commun. 41, 477 (1982).

${ }^{23}$ J. W. Allen, J. Phys. C 2, 1077 (1969).

${ }^{24}$ M. Godlewski, J. Appl. Phys. 56, 2901 (1984)

${ }^{25} \mathrm{P}$. Vogl and J. M. Baranowski, in Proceedings of the 17th International Conference on the Physics of Semiconductors, San Francisco. 1984, edited by J. D. Chadi and W. A. Harrison (Springer, New York, 1985), p. 623.

${ }^{26}$ B. Deveaud, B. Plot, B. Lambert, G. Bremond, G. Guillot, A. Nounilhat, C. Naud, and B. Clerjaud, J. Appl. Phys. (to be published) 